\title{
SILICOSIS AND CARCINOMA OF THE LUNG
}

\author{
By C. S. ANDERSON AND J. HENRY DIBLE \\ From the Department of Pathology, the University of Liverpool \\ (With Plates VIII and IX)
}

Chronic irritation is a recognized factor in the causation of malignant epithelial growths and it would not, a priori, be surprising if an association were found to exist between pneumokoniosis and pulmonary cancer. With the notable and somewhat questionable exceptions of the observations upon Schneeberg and Joachimstal miners there has, however, been little to support this view. Nevertheless certain observations of ours (Dible, 1934) have urged us to examine the relationship of silicosis to malignancy in a more specific and comprehensive fashion than has hitherto been achieved. This paper records the results of our investigations, which it is thought may bear upon the aetiology of the condition.

Many factors have been suggested as of causal importance in lung cancer, and the inhalation of irritating substances has been canvassed by a number of workers. Duguid (1927), from a high incidence of the disease in transport workers, suggests a combination of chronic bronchial catarrh and road dust. Frommel (1927) suggests mineral and vegetable dusts; Wolf (1895) and Schmorl (1925) suggest anthracosis; whilst the effects of road tar, petrol fumes, tobacco, specific chemicals, silica, and certain industrial metallic dusts have at times been mentioned. The most noteworthy observations from our point of view are however those of Rostoski et al. (1926) upon the cancer of the lung which occurs in the Schneeberg miners. In the course of an investigation lasting over a period of more than 3 years these workers examined 154 miners, of whom 116 were still at work. By $\mathrm{X}$-ray examination twenty of these individuals were found to be suffering from pneumokoniosis and in seventeen of them tumours of the lung were found. Four more neoplasms were discovered in the subsequent progress of the work. All the subjects who showed tumours also showed pneumokoniosis but, as would be expected, a number of miners who showed pneumokoniosis did not show tumours. The same investigators examined 362 members of the non-mining population in this district and in them found neither pneumokoniosis nor tumour.

Schmorl (1926), who investigated the morbid anatomy of these cases, found that the malignant disease was associated with "anthracochalicosis". $\mathrm{He}$ (Schmorl, 1925) had previously concluded that small bronchial carcinomata might arise in cicatrices resulting from the breaking through of softened 
"anthracotic" lymph nodes into the bronchial tubes (see also Saupe, 1933). He found many similar cicatricial changes in the Schneeberg cases and suggested that here too the carcinomata may have had a similar origin. Schmorl nevertheless appears to conclude, and this opinion is shared by most of the writers upon Schneeberg cancer, that it is on the whole improbable that the anthracochalicosis is the direct cause of the lung cancer but that a further factor peculiar to these mines is the important one. It is of more than passing interest to note that in a large proportion of his cases he found more than one primary growth in the lung. Pulmonary tuberculosis was found in six cases.

Some analogous observations were made at the Joachimstal uranium mines which are only $30 \mathrm{~km}$. from Schneeberg [Lowy, 1929; Doubrow, 1931; Sikl, 1930 and especially Pirchan \& Sikl, 1932 and Saupe, 1933]. The workers last referred to found, during the period 1929-30, in thirteen post-mortems upon miners, that lung cancers were present in nine of them, associated in a number of cases with moderate degrees of silicosis or anthracosis: of the rest of this series, one died from accident, one from "cirrhosis of the lungs", and two from tuberculosis. The average age in the cases of lung carcinoma was 50 years and the duration of the employment 17 years. The growths were oat-cell carcinoma in five cases, pleural carcinoma in one and squamous-cell in two. In one instance two primary growths were found. They comment on the absence of advanced anthracosis or silicosis in these cases and do not attach aetiological importance to pneumokoniosis, but tend rather to implicate the radioactive substances to which the workers were exposed. It is interesting to note that though these mines have been worked since the early part of the sixteenth century, and the frequency of lung disease had long been recognized amongst the miners, as late as 1921 a specific enquiry as to the presence of cancer of the lung in this industry was answered in the negative, and it was only after the publication of Lowy's paper in 1929 that official attention was drawn to the matter and the true state of affairs became known.

In only one case in the series reported by Pirchan \& Sikl was the lung examined chemically. Here calcium, magnesium, aluminium and silicic acid were found, but radioactive substances, arsenic, bismuth, cobalt and nickel were not found. The reported results were only qualitative. The conditions in these mines are peculiar as the minerals have a high arsenical content, and sulphur, cobalt and nickel as well as silica are also present. In addition the dust is charged with radium emanation and the opinion has been generally held that this, or an agent other than silica which is present in the mineral dust of these mines, is the important one; more especially since no such correlation between silicosis and pulmonary carcinoma has been recorded in other industries in which the incidence of silicosis is high.

Apart from the Schneeberg and Joachimstal cases, in which the conditions, as we have said, are peculiar, Dible (1934) reported three cases of lung cancer in silicotics in West Lancashire: in one of these two primary growths were present in the lung and a columnar-celled carcinoma in the colon: in a third 
case of advanced silicosis a bile-duct carcinoma had developed at the site of dense basal pulmonary adhesions between diaphragm and liver and in this case an independent carcinoma of the prostate was found. Fine \& Jaso (1935) describe one case of carcinoma of the bronchus in a series of twenty-one cases of silicosis: they consider the association of these conditions commoner than is generally admitted. Allen (1934) reports two cases of bronchogenic carcinoma associated with pneumokoniosis: the view is expressed that the association was fortuitous. Pancoast \& Pendergrass (1933) record three cases of bronchogenic carcinoma with pneumokoniosis (one being Allen's first case which we have just mentioned); Klotz \& Simpson (1932), in North Ontario, report one case of carcinoma in twenty-one cases of pulmonary silicosis in miners. Whilst no comments on any association of the two conditions are made by either Sladden (1933) or Fowweather (1934), in their work on the silica content of the lung, it may be noted that the former, in a series of sixty cases, reports three examples of pulmonary carcinoma: in one of these the silica content was considerably in excess of the normal and in another there was probably an excess, although from the form in which the results are given this is not certain. Fowweather similarly records three cases of malignant disease in silicotics; one of these was pulmonary but the site of the others was unspecified. Gloyne (1935) records two cases of squamous carcinoma of the lungs in association with asbestosis and Lynch \& Smith (1935) one case of cancer of the lung in "asbestosilicosis". Further, Strachan and Simson at the Johannesburg International Conference in 1930 stated: "We have met with seven cases of carcinoma in a series of European miners, all being carcinomata of the bronchi."

To these published cases we would add three others, kindly sent to us by Dr Gough of the Welsh National School of Medicine, which showed advanced silicosis with carcinoma. One of these patients also suffered from an epithelioma of the ear.

\section{The PResent investigation}

We have concerned ourselves with the following main points:

(1) The estimation of the total silica content of the lungs of subjects not having cancer of the lung.

(2) The total silica content of the lungs of seventy individuals dying of primary cancer of the lung.

(3) The histological evidence of pneumokoniosis in the latter subjects.

Technique. The silica estimations were carried out upon the whole lung as a routine, the content of each lung being estimated separately. In a few cases only portions of the lungs were available and these are indicated later in the tabulated results. It has been shown (Collins \& Dible, 1935) that the expression of the total silica in the lung is the only really satisfactory way of indicating the silica content of the pulmonary tissue. This form of expression has been adopted by us. The lungs were freed of all extraneous material by careful dissection, but those lymph glands which are usually impossible of removal in 
cases of cancer were left in the non-cancerous lungs. Prior to being submitted to analysis the lungs were examined closely with the naked eye and small portions were removed for histological investigation. Wherever possible the estimations were made on the fresh organs. In certain cases in which this was impossible the lungs were preserved in $10 \%$ formalin after having been weighed in the fresh state: these cases are indicated in the tables. Control experiments upon formalin-preserved and fresh lungs showed that this procedure did not affect the results.

The lungs having been weighed were cut into small portions with scissors to facilitate drying and were then dried to constant weight at $100^{\circ} \mathrm{C}$. in an oven: this took on an average about $48 \mathrm{hr}$. The dried lung was weighed and ground in a coffee-grinding machine, the weight was again checked and the material, now almost in powder form, was thoroughly mixed and stirred to ensure even distribution of its constituents. $5 \mathrm{~g}$. of the powder was generally used for the actual assay. The material was ashed in a platinum dish in a muffle furnace until all carbon was consumed and the weight of the ash was recorded. The powdered ash was mixed intimately with about twelve times its weight of fusion mixture or pure sodium carbonate, and treated for a further period of about $3 \mathrm{hr}$. in a Davies crucible furnace. This fusion is necessary for the decomposition of those silicates which are not attacked by hydrochloric acid. The fused material after being slowly cooled was transferred to an evaporating dish and dissolved in about 25 c.c. of $20 \%$ hydrochloric acid and the solution evaporated to dryness upon a water-bath. A further 20 c.c. of $20 \% \mathrm{HCl}$ were added, the evaporation repeated, and the residue dried at $110^{\circ} \mathrm{C}$. for $1 \mathrm{hr}$. After cooling 1.0 c.c. of concentrated $\mathrm{HCl}$ was added, followed by 19 c.c. of hot water. This was simmered on the water-bath for about 15 min. and filtered through a Whatman No. 44 (ash-free) paper. The residue on the filter, which represents the greater part of the $\mathrm{SiO}_{2}$ present, was washed with hot water until the washings were free of chlorides and put aside as "residue A". The filtrate and runnings were collected in a dish and the process of evaporation and filtration repeated. The second filtration resulted in the collection of a small additional quantity of silica-residue B. In the case of frankly silicotic lungs this small quantity may be neglected. The filter papers containing the two residues, $\mathrm{A}$ and $\mathrm{B}$, were dried and then slowly heated and finally ignited together for $1 \mathrm{hr}$. in a platinum dish in the crucible furnace and then weighed: this weight gives the amount of crude silica. To the residue of crude silica in the platinum dish $1 \cdot 0$ c.c. of water, plus $5 \cdot 0$ c.c. of pure hydrofluoric acid and $0 \cdot 2$ c.c. conc. sulphuric acid, were added. The effect of the hydrofluoric acid is to decompose the silica to form water and volatile silicon fluoride; the sulphuric acid absorbs water and prevents the formation of gelatinous silica which would otherwise occur. The solution is then evaporated on the water-bath until only $\mathrm{H}_{2} \mathrm{SO}_{4}$ is left, a further $2 \cdot 0$ c.c. of hydrofluoric acid are again added and the whole evaporated to dryness and the residue incinerated for $30 \mathrm{~min}$. in the furnace. The process is repeated until the weight of the residue remains constant. This final weight gives the weight of non-volatile substances after treatment with hydrofluoric acid, and when subtracted from the weight of crude silica, gives the weight of pure silica. The chemical process is based upon notes kindly supplied by Dr Fowweather of Leeds and the methods given by Clowes \& Coleman (1931).

The method employed of drying and powdering the whole lung has the advantage that it obviates errors which would arise from variations in the distribution of silica in different parts of the organ and allows the accurate expression of the total silica in the lung. In view of the small amounts of silica found the greatest care had to be taken to secure accuracy in the extractions. Blank experiments were carried out with each fresh batch of reagents. It was 
found that especial attention to the following points was necessary: the complete oxidation of the dried lung during combustion and the avoidance of any loss in the process; efficient fusion-indicated by the small amount of nonvolatile residue; the avoidance of loss due to frothing when dissolving the fused mixture; the avoidance of loss of the light silica powder in the ignition of the filter papers; and the cooling of all residues in a desiccator prior to weighing.

\section{RESUlts}

\section{(A) Results in lungs not the seat of malignant disease}

Fifty cases were analysed in this series of which forty were males and ten females. The lungs were not specially selected except that cases of malignant disease were excluded as were also examples of gross pathological abnormality. Otherwise they represent the general run of post-mortem material from two general hospitals in Liverpool. The complete results are given in Table I.

In calculating the mean results two cases have been excluded. Case no. 31 was a child; this being the only child in the series. Case no. 38, which was also a young subject, only showed a trace of silica. Except for the factor of age we are unable to account for the extremely low content, and no technical error was discovered, although we cannot affirm the impossibility that such may have occurred. Since this was the only case in this fairly large series giving such a result it was thought right to exclude it, although its inclusion would not materially affect the results.

\section{(B) Results in lungs the seat of primary carcinoma}

Seventy cases were analysed in this series of which sixty-one were males and nine females. No selection was exercised, the lungs being used as they were received from the same two general hospitals which supplied the control material. It may be mentioned that this number represents something a little less than the total incidence of the disease in the autopsies from some 1200 medical beds in this district in a period of 18 months-since we were not able to deal with quite all the cases which were found. The results obtained are given in Table II under the same headings as those in the non-carcinomatous lungs, except that in the malignant series the type and site of growth is indicated.

\section{(C) Criteria, and analysis of chemical findings}

As an index of normal variability in the quantity of silica in the lungs use has been made of the generally accepted statistical measurement, the standard deviation. Any quantity in excess of the mean content, in the control series, plus three times its standard deviation, has been considered to be abnormally high. Taking the total silica in the two lungs together: the mean figure is $0.262 \mathrm{~g}$. and the standard deviation $(\sigma)$ is 0.048 ; hence any case with a silica content falling outside the limits $0 \cdot 262 \pm(3 \times 0 \cdot 048)=0 \cdot 262 \pm 0 \cdot 144$; i.e. $0 \cdot 12$ and $0.41 \mathrm{~g}$. may be regarded as abnormal. 

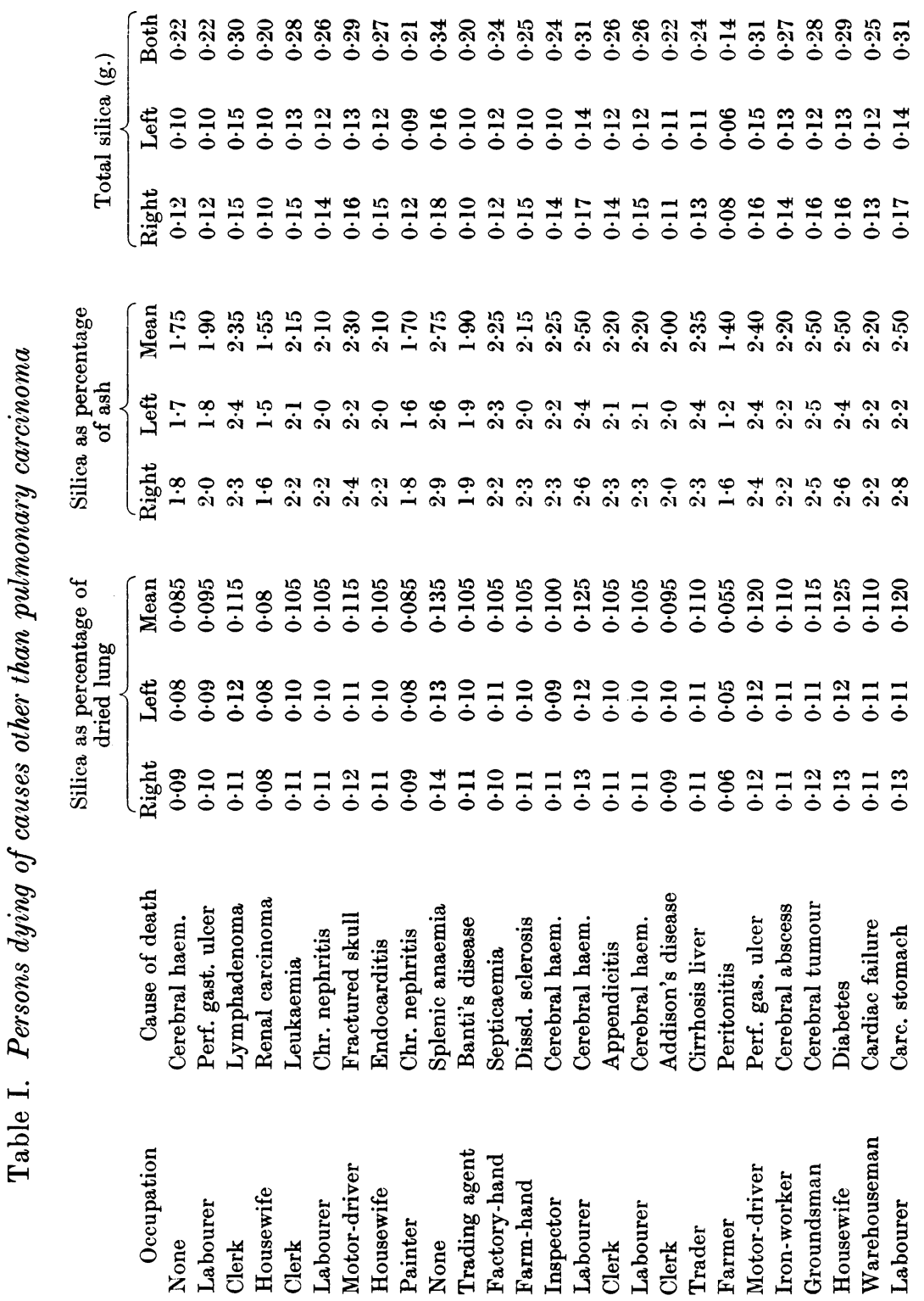

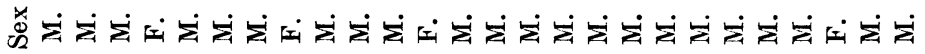

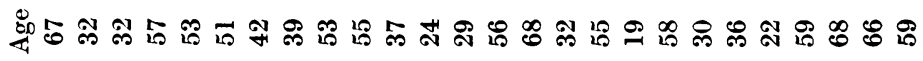

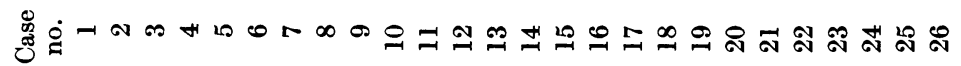




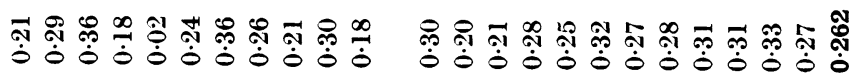

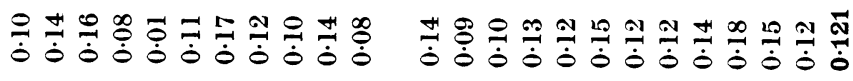

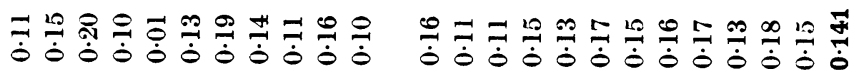

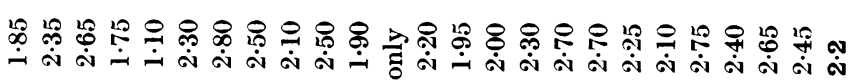

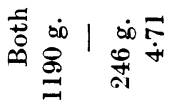

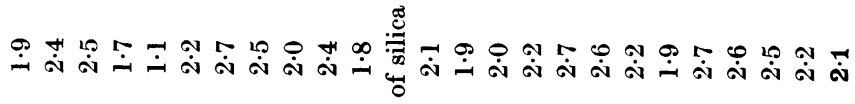

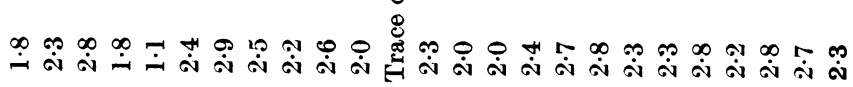

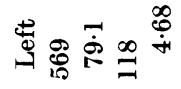

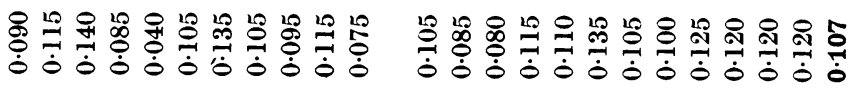

营苟

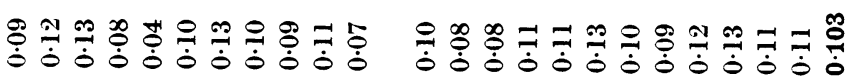

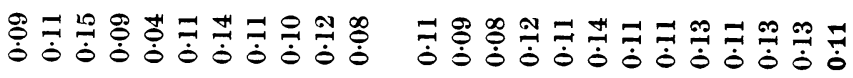

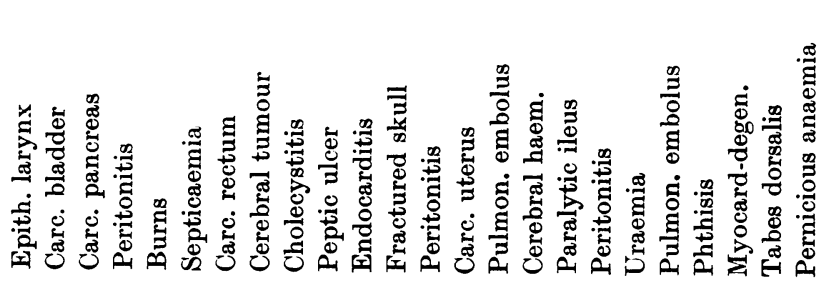

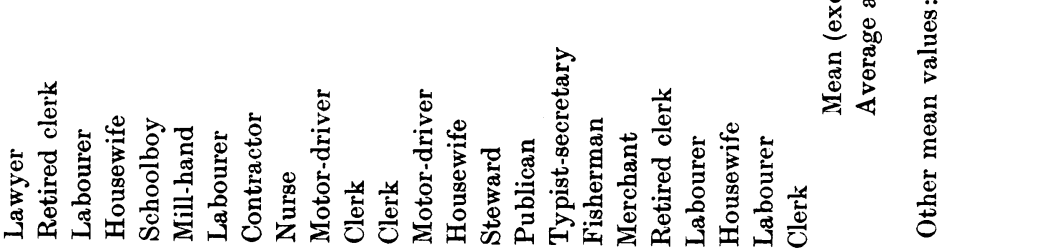

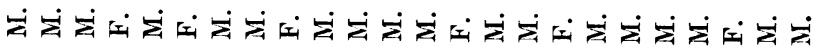

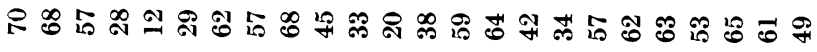

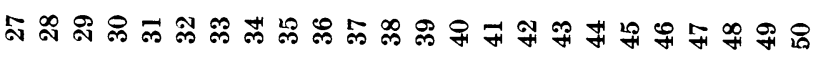




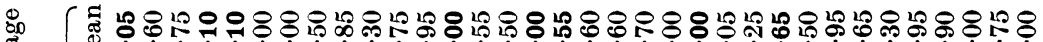

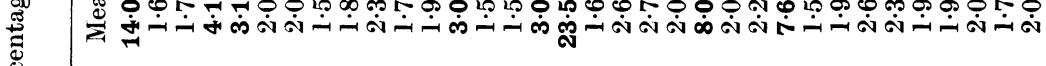

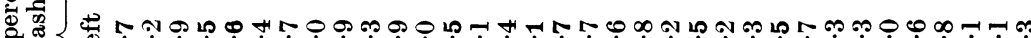
3 تص 远

닌

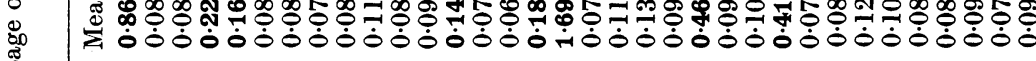
:

년

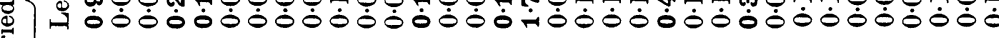
สิ 荧

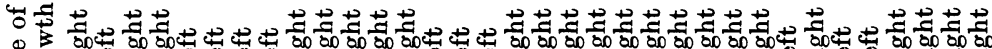

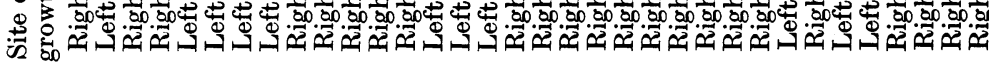

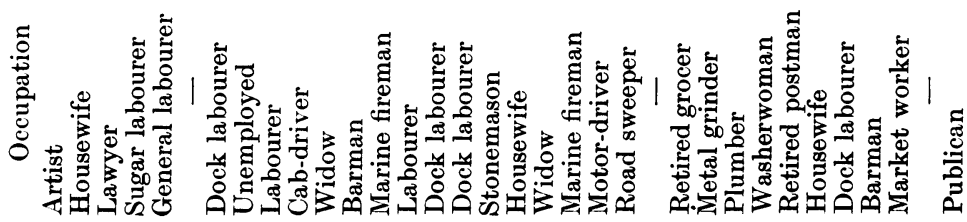

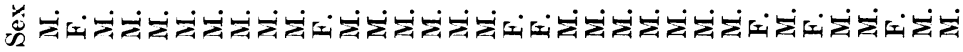

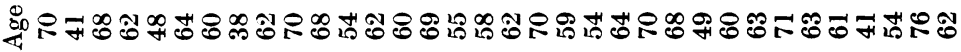

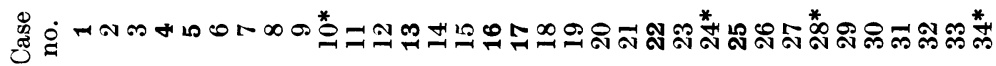




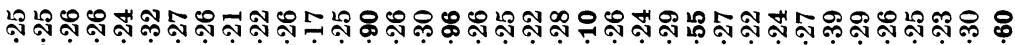

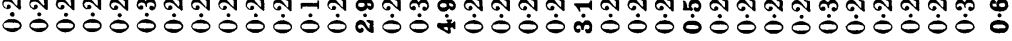

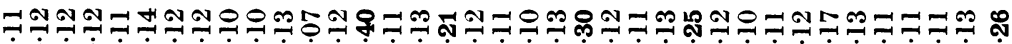

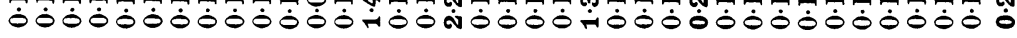

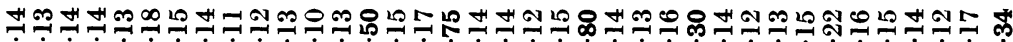

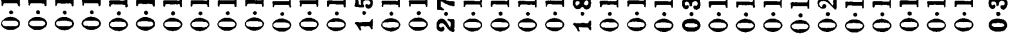

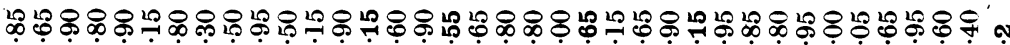

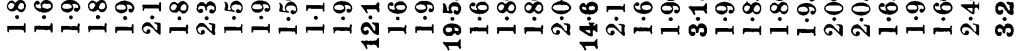

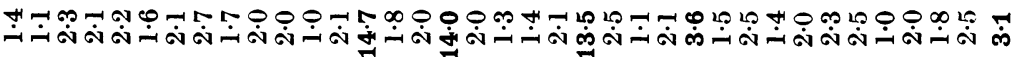
מ

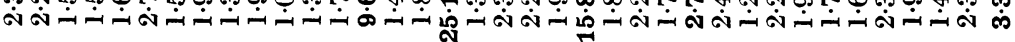

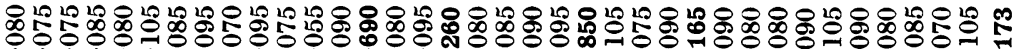

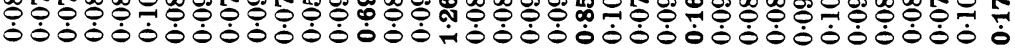

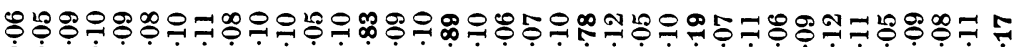

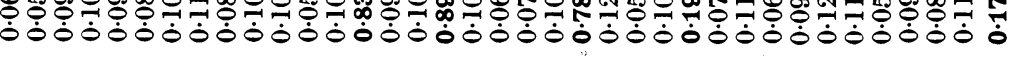

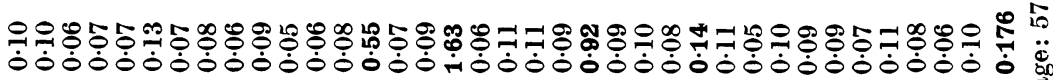

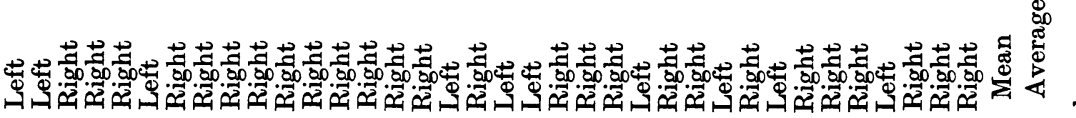

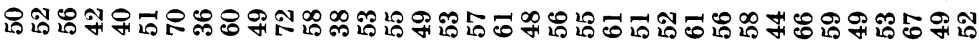

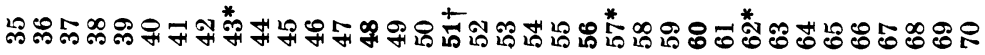


The lower figure obtained in this way may serve to some extent as a test of the accuracy of our technique, and it will be seen that in none of the admissible cases in either series-118 in all-is the silica content as low as $0 \cdot 12 \mathrm{~g}$. Further, in the non-carcinomatous lungs in no case is the upper figure reached.

If we apply these criteria to the carcinomatous lungs we find that there are twelve cases in which the upper limit is exceeded; the values varying from 0.42 to $7 \cdot 3 \mathrm{~g}$. These are printed in heavy type in Table II. We may to some extent summarize these findings by giving the mean figures for the total silica found in the different classes of case.

Table III. Mean results in different categories

\begin{tabular}{|c|c|c|c|c|c|}
\hline & \multirow[b]{2}{*}{$\begin{array}{l}\text { No. exa- } \\
\text { mined }\end{array}$} & \multirow[b]{2}{*}{ Age } & \multicolumn{3}{|c|}{ Total silica } \\
\hline & & & $\begin{array}{l}\text { Right } \\
\text { lung }\end{array}$ & $\begin{array}{l}\text { Left } \\
\text { lung }\end{array}$ & $\begin{array}{l}\text { Both } \\
\text { lungs }\end{array}$ \\
\hline Non-carcinomatous lungs* & 48 & $49 \cdot 2$ & $0 \cdot 14$ & $0 \cdot 12$ & $0 \cdot 26$ \\
\hline Total carcinomatous lungs & 70 & 57 & $0 \cdot 34$ & $0 \cdot 26$ & $0 \cdot 60$ \\
\hline $\begin{array}{l}\text { Carcinomatous lungs with definite silica } \\
\text { excess }\end{array}$ & 12 & $\mathbf{5 7 \cdot 5}$ & $\mathbf{1} \cdot \mathbf{3 0}$ & 0.99 & $2 \cdot 29$ \\
\hline $\begin{array}{l}\text { Carcinomatous lungs without definite } \\
\text { silica excess }\end{array}$ & 58 & 57 & $0 \cdot 14$ & $0 \cdot 12$ & $0 \cdot 26$ \\
\hline
\end{tabular}

Before we proceed to the histological side of the work there are certain factors which need a short discussion, and also some incidental observations which arise from the statistical data. Age.

It may be said in criticism that the silica content tends increase with age, as indeed a glance over the results in Table I may suggest, and it might appear that some part at least of the higher mean silica content in the malignant cases may be due to their greater average age. An analysis of the relationship of age to silica content in our control series gives the following results:

$\begin{array}{ccccccc}\text { Age } \ldots & \ldots & A d .30 & 30-40 & 40-50 & 50-60 & 60-70 \\ \text { No. of cases } & & 6 & 10 & 4 & 15 & 13 \\ \text { Total silica g. } & & 0 \cdot 23 & 0 \cdot 24 & 0 \cdot 28 & 0 \cdot 27 & 0 \cdot 27\end{array}$

It is clear from this that the increase is not great, and such as it is, tends to show itself chiefly in the earlier decades of life.

There is no significant difference between the mean age of our cases of carcinoma with an excess of silica and those without this. The average age of our whole series is a little higher than that given by Hill (1934) who in a survey of 981 reported cases of this disease found the average to be 51 ; the period of greatest incidence being in the 5th and 6th decades.

Sex.

The mean figure for the silica content in the ten female control cases is slightly less than in the thirty-eight males, being $0 \cdot 24$ as against $0 \cdot 27$. In the carcinoma series sixty-one were males and nine females. Hill found the sex incidence, in 1374 cases, to be $78 \%$ males and $22 \%$ females. It is noteworthy that all our cases which showed an excess of silica were males. 


\section{Occupation.}

The commonest occupation in the control series was that of labourer: the two individuals showing the highest silica content were thus described but other labourers in the series showed average, or less than average, figures; this term however embraces so many totally distinct occupations that it is meaningless. Four motor-drivers showed respectively $0 \cdot 29,0 \cdot 31,0 \cdot 30$ and $0 \cdot 30 \mathrm{~g}$. of silica; the quantity in each case being slightly in excess of the mean. In the individuals with pulmonary carcinoma who did not show an excess of silica the commonest occupation was again that of labourer. In the twelve cases in which there was an abnormally high silica content the occupations were given as: stone mason, quarry worker, metal grinder, worker in abrasive soap factory, grave-digger, ${ }^{1}$ artist, sugar-house labourer, general labourer, ex-motor-driver, dock labourer, marine fireman. It will be noted that four and possibly five of these individuals followed occupations in which silicosis is a definite risk, whilst those of marine fireman, road sweeper and motor-driver may be regarded as dusty ones.

\section{Site of growth.}

In the cases with an excess of silica the growth was in the right lung in nine and in the left in three. In the cases without an excess of silica the growth was in the right lung in thirty-nine and in the left in seventeen. Hill found a slight preponderance of cases in the right lung in a review of 2000 cases.

Cause of death in individuals showing a high but questionably significant silica content in lung

The cases which showed the largest quantities of silica, but in which this was not sufficient to be considered statistically significant, succumbed to the following diseases:

\begin{tabular}{|c|c|c|}
\hline \multicolumn{3}{|c|}{ Carcinoma of lung series } \\
\hline $\begin{array}{l}\text { Case no. } \\
\quad 65 \\
20\end{array}$ & $\begin{array}{c}\text { Total silica } \\
0 \cdot 39 \\
0 \cdot 37\end{array}$ & $\begin{array}{l}\text { Cause of death } \\
\text { Carcinoma of lung } \\
\text { Carcinoma of lung }\end{array}$ \\
\hline \multicolumn{3}{|c|}{ Control series } \\
\hline $\begin{array}{l}\text { C } 29 \\
\text { C } 33\end{array}$ & $\begin{array}{l}0 \cdot 36 \\
0.36\end{array}$ & $\begin{array}{l}\text { Carcinoma of pancrea } \\
\text { Carcinoma of rectum }\end{array}$ \\
\hline
\end{tabular}

The "normal" silica content of the lung

Our investigation of the lungs of forty-eight adults in whom no pulmonary neoplasm was present provide certain useful data as to the quantities of silica which normally may be expected to be found in these organs. The data are given in detail in Table I, but we summarize our mean results here for the convenience of those interested in this matter.

\footnotetext{
1 This occupation involves a definite risk in this district which is largely a sandstone one, and we have seen at least one case of silicosis in a man so employed, and others in men engaged in laying sewers, etc.
} 


$\begin{array}{lccc} & \text { Table IV } & & \\ & \begin{array}{c}\text { Silica: as \% } \\ \text { of dried lung }\end{array} & \begin{array}{c}\text { Silica: as } \% \\ \text { of ash }\end{array} & \text { Total silica } \\ \text { Right lung } & 0 \cdot 110 & 2 \cdot 30 & \text { g. } \\ \text { Left lung } & 0 \cdot 103 & 2 \cdot 1 & 0 \cdot 141 \\ \text { Mean (both lungs) } & 0 \cdot 107 & 2 \cdot 20 & 0 \cdot 121 \\ \text { S.D. of mean } & \sigma \pm 0.0162 & \pm 0 \cdot 3209 & 0 \cdot 262 \\ & & \pm 0.048\end{array}$

It will be noted that the right lung by all methods of expression shows a larger silica content than the left. In giving expression to the quantity of silica in the organ, for reasons which we have explained we prefer to use the figure for the total silica in all cases in which there has not been excessive loss of lung substance, since this value is not influenced by the presence of exudates or other infiltrating material which may modify the figures for other methods of expression (Collins \& Dible). Our figures are, generally speaking, slightly lower than those of other workers. Thus Cummins \& Sladden (1930) in the dried lung found an average content of $0.125 \%$. Fowweather (1934), in five cases, $0 \cdot 12-0 \cdot 2 \%$, with a mean of $0 \cdot 16 \%$; McNally (1933) in twenty-one individuals who showed less than $0.2 \%$ of silica (which he takes as the upper normal limit), finds an average figure of $0.113 \%$. As a percentage of ash, Cummins \& Sladden give a mean from six cases of $2 \cdot 4$, and the same workers find the total silica in both lungs to be about $0.29 \mathrm{~g}$. It is difficult to say to what this slight but constant difference is due; it may arise in the technique, although the method we have employed has been fundamentally similar to that used by other workers; on the whole, however, we think it most probably lies in the fact that we have always used the whole lung for our assays rather than selected samples.

\section{(D) Histological investigation}

A careful microscopical examination of all the lungs which were the seat of carcinoma was made in order to detect any evidence of silicotic or other forms of fibrosis and also to determine the type of growth. No particular routine was followed, each lung being treated as seemed best for this purpose and such sections being taken as appeared desirable, but especial attention was paid to the growth and its environs and also to any areas of noteworthy fibrosis or pigmentation. All the non-malignant lungs were similarly dealt with, about four areas from each being cut to serve as histological controls.

It may be said at once that no evidence of fibrosis was obtained in the control lungs which was comparable with that which was found in the majority of those lungs which were the seat of malignant disease and which also contained an excess of silica. The latter fell into three groups, examples from each of which are shown in the illustrations.

(1) Those which showed typical whorled silicotic nodules (Figs. 1 and 2). Seven cases came into this category, viz. nos. 1, 17, 22, 25, 48, 51 and 56. The mean total content of silica in this class was $3.54 \mathrm{~g}$.

(2) Those showing areas of confluent fibrosis, which were suggestive of silicotic fibrosis but in which typical whorled nodules were not found (Figs. 3 
and 4). Three cases came into this category, viz. nos. 4, 5 and 60 . The mean total content of silica was $0 \cdot 61 \mathrm{~g}$.

(3) Those which showed degrees of fibrosis which at the most would arouse only a suggestion of silicosis (Fig. 5). There were two cases in this class, viz. nos. 16 and 13 . The mean total content of silica was $0.45 \mathrm{~g}$.

It is hardly necessary to state that our estimate of the degree of fibrosis was based, as far as possible, upon the unaffected lung, or the unaffected portion of lung where both were the seat of growth, and that the fibroses which we are describing were not stromal reactions due to the presence of growth. In all the cases the fibrotic lesions were associated with doubly refractile particles suggestive of silica and with an excess of carbon pigment.

With regard to the lungs which were the seat of carcinoma but which did not contain an excess of silica. Here again fibrosis in the healthy portions of the lung did not in any sense reproduce the picture found in those organs in which silica was present in excess.

The histological character of the growths in a number of instances showed some variation where sections from different areas were examined, and sometimes this variability was to be seen in the same section; the histological classification which we have adopted, which is based upon the predominating type of cell in the sections which we have examined, divides the growths into $(a)$ squamous cell carcinoma, (b) oat-cell carcinoma, which includes the anaplastic types of growth in which the cells are fusiform or practically round, and (c) adeno-carcinoma, embracing such as showed a definite production of gland acini.

The findings in the twelve cases in which carcinoma was associated with an excess of silica are summarized in the following table which is followed by fuller details of these cases.

\begin{tabular}{|c|c|c|c|c|c|}
\hline \multicolumn{6}{|c|}{ Table V } \\
\hline $\begin{array}{c}\text { Case } \\
\text { no. }\end{array}$ & Age & $\begin{array}{l}\text { Silica \% } \\
\text { of dried } \\
\text { lung }\end{array}$ & $\begin{array}{l}\text { Total } \\
\text { silica } \\
\text { g. }\end{array}$ & Type of carcinoma & Extent of fibrosis \\
\hline \multicolumn{6}{|c|}{ Histological group I: } \\
\hline 17 & 58 & 1.69 & $\mathbf{7 \cdot 3 0}$ & Oat-cell & Numerous typical silicotic nodules \\
\hline 51 & 53 & $1 \cdot 26$ & $4 \cdot 96$ & Squamous cell & Ditto \\
\hline 1 & 70 & 0.87 & $3 \cdot 50$ & Squamous cell & Ditto \\
\hline 56 & 55 & 0.85 & $3 \cdot 10$ & Squamous cell & Ditto \\
\hline 48 & 53 & 0.69 & $2 \cdot 90$ & Squamous cell & Ditto \\
\hline 22 & 64 & $0 \cdot 47$ & $1 \cdot 70$ & Oat-cell & Ditto \\
\hline 25 & 48 & $0 \cdot 42$ & $1 \cdot 30$ & Oat-cell & $\begin{array}{l}\text { Diffuse fibrotic areas with a few } \\
\text { small silicotic nodules }\end{array}$ \\
\hline \multicolumn{6}{|c|}{ Histological group II: } \\
\hline 4 & 62 & 0.22 & $0 \cdot 71$ & Squamous cell & Fibrotic areas but no nodules \\
\hline 5 & 48 & $0 \cdot 17$ & $0 \cdot 56$ & Oat-cell & A few ditto \\
\hline 60 & 61 & $0 \cdot 17$ & 0.55 & Oat-cell & Fibrosis with confluent areas \\
\hline \multicolumn{6}{|c|}{ Histological group III: } \\
\hline 16 & 55 & $0 \cdot 18$ & $0 \cdot 49$ & Squamous cell & $\begin{array}{l}\text { A little diffuse fibrosis. Silicotic } \\
\text { nodule in gland }\end{array}$ \\
\hline 13 & 62 & $0 \cdot 15$ & $0 \cdot 42$ & Squamous cell & $\begin{array}{l}\text { Multiple fibrous anthracotic no } \\
\text { dules }\end{array}$ \\
\hline
\end{tabular}

[Cases no. 17 and 48 showed associated foci of tuberculosis.] 
With regard to the correlation between silica content and histological change, we would recall that Cummins \& Sladden (1930) in nineteen cases of coal-miner's lung showing whorled nodules found the total silica in the lungs to range between 1.2 and $20.2 \mathrm{~g}$., with a mean of $7.6 \mathrm{~g}$. In eleven cases with confluent fibroses, but without nodules, the range was from $1 \cdot 0$ to $7 \cdot 9 \mathrm{~g}$., with a mean of $3 \cdot 6 \mathrm{~g}$. It has been pointed out that the estimates of these workers tend to be consistently a little higher than ours, but it will be seen that the values in all our cases with nodules fall within the range covered by their cases with this histological condition.

Case details. We give here the main details which are of importance on the twelve cases of carcinoma in which we found a statistically significant increase in silica content of the lung. The cases are presented in order of decreasing silica content. The reference number to the main table (Table II, pp. 192, 193) is given in each case.

\section{Cases in Histological group $I$}

Case 17. Male, aet. 58. Road worker, formerly a stonemason.

Right side. Pleura adherent. Numerous pearly nodules on visceral pleura and adhesions containing calcified plaques. Growth around lower bronchus at entrance to lung and infiltrating along bronchus: large portions of tumour necrotic. Numerous fibrotic nodules, some as large as a pea, throughout the lung: some areas of tuberculosis. Hilar and bronchial glands invaded by growth.

Left side. Pleura thickened; some adhesions. Fibrosis of lung as on right side but nodules fewer. Glands fibrotic, not invaded by growth.

Metastases in liver, brain and vertebrae.

Microscopical examination. Many typical whorled silicotic nodules and areas of dense silicotic fibrosis. Many doubly refractile particles present. Fair amount of carbon. Growth predominantly oat-celled. Areas of tuberculosis present in right lung.

Case 51. Male, aet. 53. Grave-digger.

Right side. A few pleural adhesions at apex. A few pearly nodules of miliary size on visceral pleura, chiefly over the upper lobe. Numerous grey-black nodules in lung especially numerous in upper lobe. Glands fibrotic.

Left side. Numerous nodules on visceral pleura. Lung nodules as on right but tending to be larger and fewer; considerable diffuse fibrosis. Tumour in upper lobe, the size of a florin surrounded by considerable fibrosis and apparently originating in one of the smaller bronchi of the upper lobe. Glands fibrotic and invaded.

Metastases in brain and supraclavicular glands. An independent adeno-carcinoma present in the left kidney.

Microscopical examination. Numerous typical whorled silicotic nodules in both lungs (Fig. 1), with doubly refractile particles. No excess of carbon. Growth mainly squamouscelled. No tuberculosis.

Case 1. Male, aet. 70. Artist.

Right side. Pleura showed numerous hard, flat, small pearly oval nodules, in visceral layer with excess of pigment. The lung shows numerous greyish black, hard nodules throughout, ranging from about 1 to about $5 \mathrm{~mm}$. in diameter; considerable diffuse fibrosis. Glands enlarged and harder than normal: no growth.

Left side. Large empyema. Pleura and uninvolved portions of lung as on right but nodules more marked especially in upper lobe. Tumour: a necrotic growth about the bronchus to upper lobe. Hilar and bronchial glands involved.

No metastases. 


\section{S. Anderson and J. Henry Dible}

Microscopical examination. Typical whorled silicotic nodules and large sclerotic confluent areas of fibrosis in both lungs showing doubly refractile particles: marked excess of carbon. Growth predominantly squamous. Typical silicotic nodules in uninvolved glands. No tuberculosis.

Case 56. Male, aet. 55. Quarry worker.

Right side. Pleura adherent over whole surface. Growth involving whole lung in quasimiliary fashion. Numerous fibrotic nodules throughout with little intervening fibrosis. Pigment not excessive. Glands involved. Bronchiectasis in lower lobes.

Left side. Pleura as on right. Lung contains fibrous nodules but free from tumour.

Metastases in liver, brain, left adrenal.

Microscopical examination. Typical whorled silicotic nodules in both lungs. Doubly refractile particles present. No excess of carbon. Growth mainly an anaplastic squamous carcinoma not invading nodules. No tuberculosis.

Case 48. Male, aet. 53. Worker in abrasive soap factory.

Right side. Pleura very adherent to parietes and between lobes. Nodules present. Lung shows numerous small grey-black nodules scattered throughout: marked fibrosis in upper lobe. Tumour at hilum occluding bronchus of upper lobe which is invaded widely with extension also into middle lobe. Glands invaded and fibrotic.

Left side. Old pleural adhesions; few nodules present. Lung as on the right side but nodules fewer. Glands fibrotic; one invaded by growth.

Metastases in liver and brain.

Microscopical examination. Typical whorled silicotic nodules in both lungs with considerable excess of carbon: doubly refractile particles present. Growth predominantly an anaplastic squamous cell carcinoma. There are a few nodules of tuberculosis in the left lung.

Case 22. Male, aet. 64. Road sweeper.

Right side. No pleural nodules. Lung shows considerable diffuse fibrosis; a few small nodules. Tumour present about bronchus of upper lobe extending into lung. An apparently separate growth, about the size of a florin, in lower part of the upper lobe. Bronchial and one hilar gland involved; glands fibrotic. Chronic bronchitis.

Left side. Except for absence of growth the conditions are the same as on the right side.

No metastases.

Microscopical examination. Many typical whorled silicotic nodules in both lungs (Fig. 2). Those in the area of growth surrounded by large amount of carbon pigment. Growth mainly of oat-cell type. No tuberculosis.

Case 25. Male, aet. 48. Metal grinder.

Right side. Old pleural adhesions: a few nodules on visceral pleura. Lung shows considerable diffuse fibrosis with scattered grey-black discrete nodules especially in upper lobe: excessive pigmentation. Tumour: a small growth of hilum extending into upper lobe. Hilar and bronchial glands fibrous and invaded.

Left side. Pleura: very rare occasional nodules. Lung as on right except for absence of tumour but nodules fewer. Glands fibrous.

Metastases in liver.

Microscopical examination. Typical silicotic nodules surrounded with carbon pigment and containing numerous doubly refractile particles. Growth predominantly oat-celled. No tuberculosis.

\section{Cases in Histological group II}

Case 4. Male, aet. 62. Sugar-house labourer.

Right side. Numerous old pleural adhesions. Lung diffusely fibrotic: no nodules. Considerable pigmentation. Growth appears to originate near entry of lower lobe bronchus and has infiltrated most of this lobe. 
Left side. Fibrosis as on right side but rather less.

No metastases.

Histological examination. Areas suggestive of silicotic fibrosis found in uninvolved portions of the lung but no typical whorls seen (Fig. 3). Doubly refractile particles present. Growth squamous-celled. No tuberculosis.

Case 5. Male, aet. 48. Labourer.

Right side. Pleura nil. Lung shows some diffuse fibrosis; no nodules. A mass of glands present at the hilum.

Left side. Old pleural adhesions especially over upper lobe. Extensive fibrosis in upper lobe, less in lower. Tumour in bronchus to upper lobe mainly limited to hilum and extending only a short distance into lung. Mass of invaded glands at hilum.

Metastases in liver, kidney, pancreas.

Microscopical examination. Considerable dense fibrosis on left side of silicotic type with doubly refractile particles. The spreading edge of the tumour can be seen invading nodules of fibrosis at a stage at which no true stroma-reaction is apparent. No typical whorls. Some excess of carbon. Growth mainly oat-cell type. No tuberculosis.

Case 60. Male, aet. 61. Ex-motor-driver.

Right side. Pleura free of nodules. Lung shows considerable diffuse fibrosis throughout: no nodules. Considerable pigmentation. Growth: a small mass involving and partly occluding bronchus to the lower lobe, with considerable extension into the lung. Hilar and bronchial glands invaded.

Left side. As for right, except for absence of tumour. Glands not involved.

Microscopical examination. Areas of confluent fibrosis present (Fig. 4): no whorls. Excess of carbon. Doubly refractile particles present. Growth predominantly oat-celled. No tuberculosis.

\section{Cases in Histological group III}

Case 16. Male, aet. 55. Dock labourer.

Right side. Pleura normal. The lung showed a little diffuse fibrosis throughout. No excess of pigment.

Left side. Old pleural adhesions over upper lobe. Considerable diffuse fibrosis throughout. No excess of pigment. A large growth at the hilum involving and occluding upper bronchus and also constricting lower: areas of growth in both lobes.

No metastases.

Histological examination. Considerable diffuse fibrosis on left side with anthracotic infiltration. One silicotic nodule in a bronchial gland invaded by growth. Some areas suggestive of silicous fibrosis but not typical. Doubly refractile particles present. Growth predominantly squamous-celled.

Case 13. Male, aet. 62. Marine fireman.

Right side. Excessive pigmentation of pleura. No unequivocal fibrosis of lung: marked anthracosis. Growth : a tumour of the upper bronchus involving the lobe: abscess in mediastinum.

Left side. Pleura as on right: questionable fibrosis of lung. Marked anthracosis.

Metastases in liver. Paget's disease in skull. Chronic duodenal ulcers.

Microscopical examination. Marked nodular anthracosis with fibrosis in both lungs (Fig. 5). Fibrosis obscured by excess of carbon pigment. Only few doubly refractile particles. Growth predominantly squamous-celled. No tuberculosis.

There are certain other points in this series to which we would draw attention.

All the cases are males. 


\section{S. Anderson and J. Henry Dible}

In all, the histological type of the growth was either squamous or of the anaplastic "oat-cell" variety. It is of interest to note that in Schmorl's Schneeburg cases twelve were squamous in type, six were carcinoma simplex and three "small-celled" carcinomata: the latter, it may be taken, would fall into our oat-cell class. Pirchan \& Sikl found five oat-cell tumours and two squamous-celled carcinoma in the series at Joachimstal. The absence of examples of adenocarcinoma may be of significance.

Pulmonary tuberculosis was present with carcinoma in two of the individuals in the silicotic group: only one case (No. 36) in the remaining fifty-eight examples of lung cancer showed this association.

As is often the case, an excess of carbon pigment was at times found in association with the silicotic fibrosis. In some of the specimens of malignant disease of the lung, without fibrosis attributable to silica, there was also an excess of carbon but in these the distribution was generally different, the carbon being chiefly in phagocytes and not extracellularly in the fibrous tissue as it was when associated with silicotic fibrosis. In one case in which we found only a slight excess of silica (No. 13, Fig. 5) the histological picture was that of a nodular fibrosis, in which the nodules were heavily impregnated with carbon which obscured all histological detail; there can be little doubt that this patchy anthracosis had a silicotic basis.

In one case (No. 22) there were apparently two primaries in the lung. One case (No. 51) also had a malignant growth of independent type in the left kidney. We have also seen, during the examination of this series, a case of silicosis with rodent ulcer and one (Dr Gough, Cardiff) of silicosis, pulmonary carcinoma, and epithelioma of the ear. Schmorl (1925) and Dible (1934) have commented upon this association.

\section{Commentary}

Our investigation has shown that there is a greater incidence of silicosis amongst those who have lung cancer than amongst those who have not. In an analysis of seventy cases of the latter disease seven of the victims showed indisputable evidence of silicosis, three showed a significant excess of silica in the lungs and a histological picture of fibrosis having the features of that set up by silica. Two other cases showed a significant excess of silica with fibrotic changes which, though not typical, were compatible with a silicious origin, and two further cases (Nos. 20 and 65, which are not included in Table V) showed a content of silica which exceeded the maximum value obtained in our control series. With these exceptions the remainder of our cases of carcinoma of the lung did not show either chemical or histological evidence of silicosis. In our examination of the lungs of fifty individuals in which lung cancer was not present silicosis was also absent.

In sum, therefore, we may say that a group of cases of pulmonary carcinoma exists in which the organs contain an excess of silica and show histological evidence 
of silicotic fibrosis. The conclusion, we think, is that the role of the silicosis is aetiological.

The alternatives to this view are that the two conditions are coincidental and unrelated; that the relationship is the reverse of what we have supposed and the silicosis the consequence of the presence of the malignant growth; or that both are related to some third factor which is causal of both silica accumulation and carcinoma.

The available evidence is against the view that the association is fortuitous. It is true that it might be said that the area in which we have worked is a sandstone district, and that silicosis is to some extent prevalent, so that chance association may account for our findings. The point is met by the results in our controls, none of which showed any evidence of silicosis. Further, our general post-mortem experience has not given us any evidence of a local unrecognized silicosis in persons dying of other diseases, let alone a condition even remotely approaching that which we have described and figured in our cases of carcinoma.

The second possibility is that the changes in the lung set up by cancer cause an accumulation of silica dust which gives the histological and chemical results we have described. It is fairly easy to dispose of this, as in most of our cases the evidences of silicosis have been quite clear in portions of the lung not involved by the growth, or in the opposite lung where the growth has been unilateral.

Lastly, there remains the further possibility that some unspecified condition may cause both cancer and an accumulation of silica giving the picture of silicosis. One cannot fail to be impressed by the normality of our cases of carcinoma of the lung when those which also suffered from silicosis are abstracted; the results when this is done being practically identical with the results in the control series (Table III). Whatever view we take of the silicosis, whether aetiological or not, it is clear that it is operative in a certain group of cases but is not associated with the residue. If its action be not aetiological, and the association with cancer be due to a third factor, we have no inkling of what this factor is. We cannot exclude the possibility that some unknows irritant, carcinogenic in action, may either specifically derange the lungs so as to cause a retention of silica, or may be associated with silica as has been assumed to be the case in Schneeberg. We are not able, however, to point to such an irritant and in its absence we suggest that silica itself is the causal factor. The necrosing and irritative effects of this material, and its influence in stimulating tissue proliferation, are well known. In the absence of any clear evidence of its carcinogenic action we must, however, limit our definite conclusions to indicating that directly or indirectly silicosis is a factor of importance in relation to a certain number of cases of carcinoma of the lung.

It may also be offered in argument that in industries in which silicosis is a recognized risk, and in which the workmen are well supervised medically, no association with carcinoma has been discovered. This is a weighty observation 
and although it does not affect the results we adduce it demands some consideration of the apparent discrepancy. It is, of course, to be recognized that conditions in one part of the world cannot be compared with those in another: there are innumerable factors of climate, race, environment, hygiene, etc. which are quite imponderable. It is also to be borne in mind that the factors of degree and period of exposure, and the prevalence of tuberculosis, weigh greatly upon the result obtained. In our cases the degree of silicosis has been mild, the age of the patients well advanced, and the duration of the disease probably very long: tuberculosis has been absent, or when present has not been a prominent feature of the pathological changes. In other areas, and especially in trades in which silicosis as such is a prominent risk, the intensity of the disease is commonly greater, the dosage is high and the period of exposure shorter; since death is apt to occur at an earlier age from the direct pulmonary or circulatory effects of silicosis, from intercurrent disease or, as seems more usual, from tuberculosis. Finally, there is the possibility of the association being present in these areas but of its being overlooked. A thing is often never found until it is deliberately sought for: we may instance the case of Joachimstal (p. 186) to which we have already referred. Our results lead us to wish that the matter might be specifically investigated by those who have access to large numbers of individuals employed in industries in which exposure to silica dust is a recognized risk. We feel that if the problem were approached not only from the statistical and industrial, but also from the pathological side, an opinion which is so commonly expressed might be revised.

\section{Acknowledgements}

We would offer our grateful thanks to Dr McWilliam, Medical Superintendent, and Dr Dawbarn, Pathologist, to the Walton Hospital in the City of Liverpool for their assistance in the provision of material; to Dr Jethro Gough, of the Welsh National School of Medicine, for allowing us the use of certain of his cases, and to Mr Caradog Jones, of the University of Liverpool, for advice upon statistics. Finally we would record that Dr Anderson was the tenant of a Holt Fellowship of this University for a portion of the time occupied by this research and of a British Medical Association Scholarship for the remainder.

\section{REFERENCES}

Allen, J. (1934). Industr. Hyg. 16, 346.

Clowes, F. \& Coleman, J. B. (1931). Quantitative Chemical Analysis, pp. 119-21, 279-83. (Churchill.)

Collins, D. H. \& Dible, J. H. (1935). J. Hygiene, 35, 64.

Cummins, S. Lyle \& Sladden, A. F. (1930). J. Path. and Bact. 33, 1095.

Dible, J. H. (1934). Lancet, ii, 982.

Doubrow (1931). Paris Méd. 79, 287.

Duguid, J. B. (1927). Lancet, ii, 111. 
Fine, M. J. \& Jaso, J. V. (1935). J. Amer. Med. Assoc. 104, 40.

Fowweather, F. S. (1934). J. Soc. Chem. Ind. 53, 713.

Frommer, E. (1927). Revue de Med. (quoted by Hill, 1934).

Gloyne, S. R. (1935). Tubercle, 17, 5.

HiLl, R. M. (1934). Edin. Med. J. 12, 320.

Klotz, O. \& Simpson, W. (1932). Libman Anniversary Volumes.

Lowy, J. (1929). Med. Klin. 25, 141.

Lynch, K. M. \& Sмith, W. A. (1935). Amer. J. Cancer, 24, 56.

MoNally, W. D. (1933). J. Amer. Med. Assoc. 101, 584.

Pancoast, H. K. \& Pendergrass, E. P. (1933). Ibid. 101, 587.

Pirchan, A. \& SikL, H. (1932). Amer. J. Cancer, 16, 681.

Rostoski, SAUPe \& Schmorl (1926). Ztschr. f. Krebsforsch. 23, 360.

SAUPE (1933). Zentral.f. inn. Med. 54, 825.

Scrmort, G. (1925). München. Med. Wchnschr. 72, 757.

Schmorl, G. (1926). Vide Rostoski, Saupe \& Schmorl (1926).

SikL, H. (1930). Ztschr. f. Krebs. 23, 609.

Simson, F. W., Strachan, A. S. \& Sovtherland, A. (1930). Records of International Conference, Johannesburg.

Slladden, A. F. (1933). Lancet, ii, 123.

Wolf, K. (1895). Fortschr. Med. 23, 725, 765 (quoted in Ewing, 1934).

\section{EXPLANATION OF PLATES VIII AND IX}

\section{PLATE VIII}

Fig. 1. Case 51. Silicotic nodules in the right lung. This lung was free from carcinoma. $\times 4$.

Fig. 2. Case 22. Silicotic nodules in the left lung. This lung was free from carcinoma. $\times 4$.

Fig. 3. Case 4. Dense fibrosis of silicotic type with particles of silica and some anthracosis, in the right lung. This area is surrounded and in places invaded by carcinoma cells. $\times 38$.

\section{PLATE IX}

Fig. 4. Case 60. Right-side. The appearances are similar to those in the previous figure. $\times 43$.

Fig. 5. Case 13. Anthracotic nodules in uninvaded lung. There is little doubt that these have a silicotic basis. $\times 4$.

(MS. received for publication 11. vi. 1937.-Ed.) 

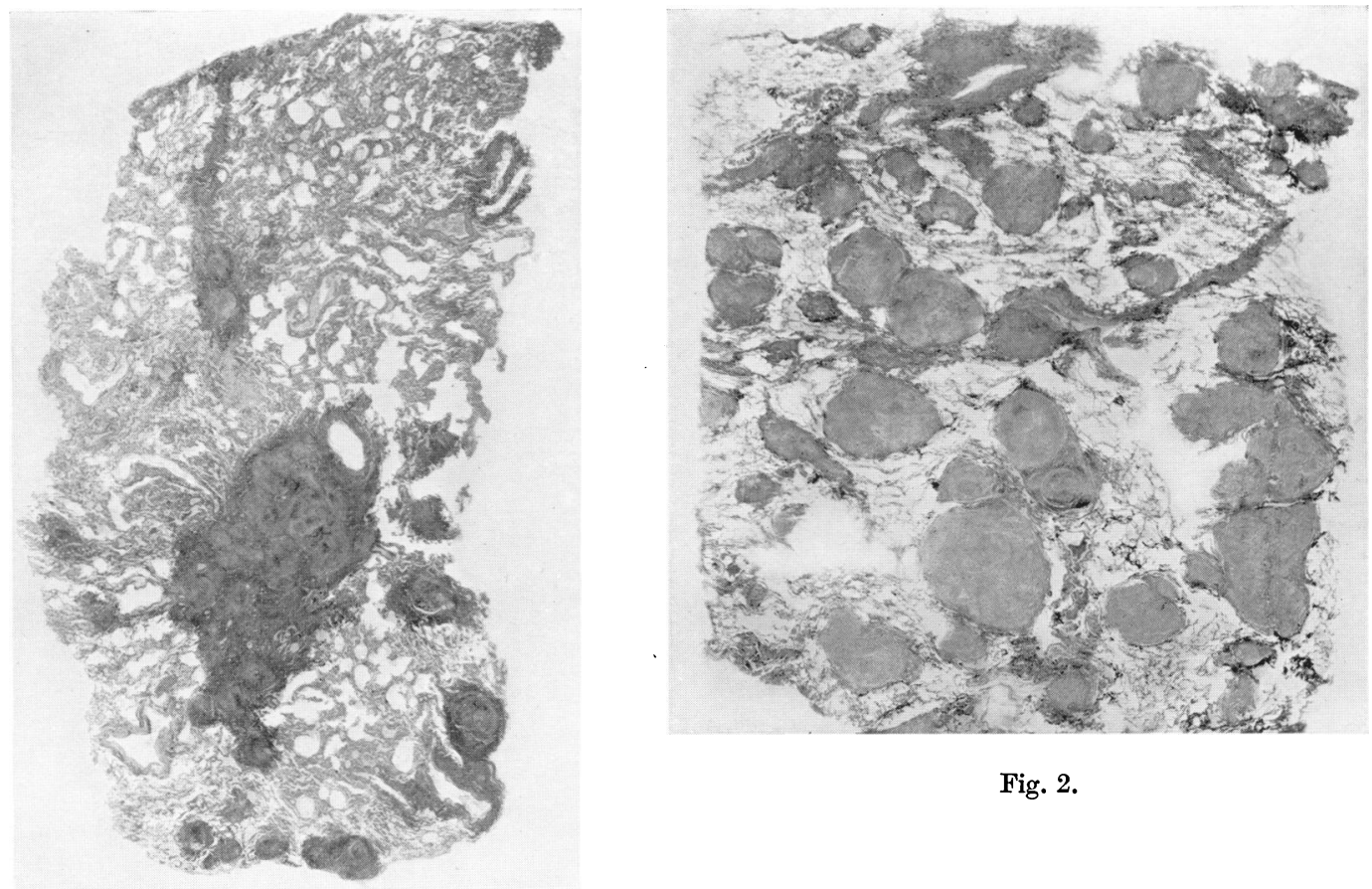

Fig. 2.

Fig. 1.

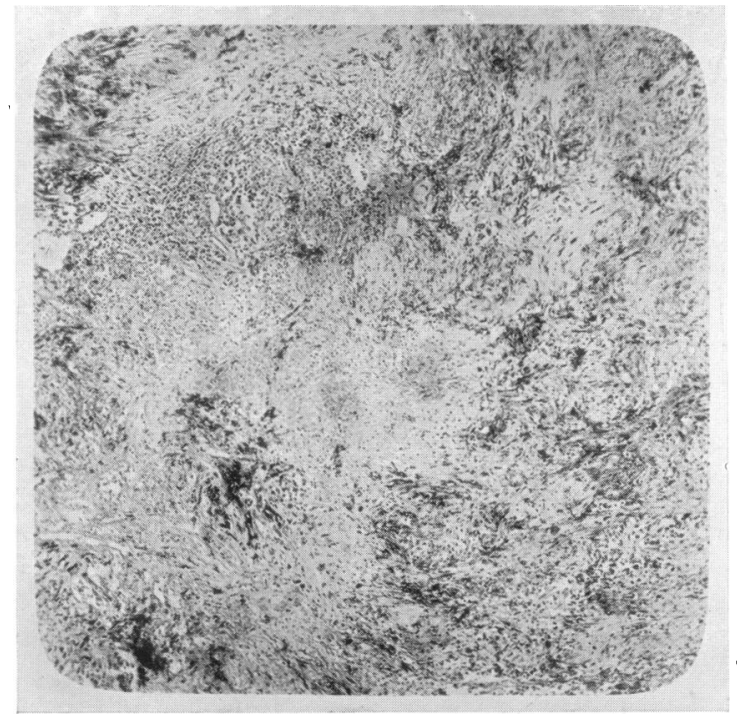

Fig. 3. 


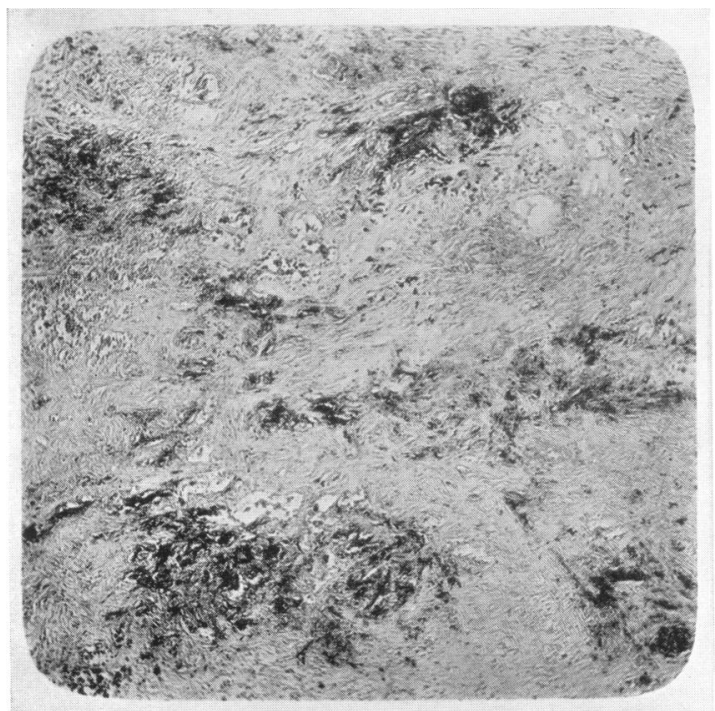

Fig. 4.

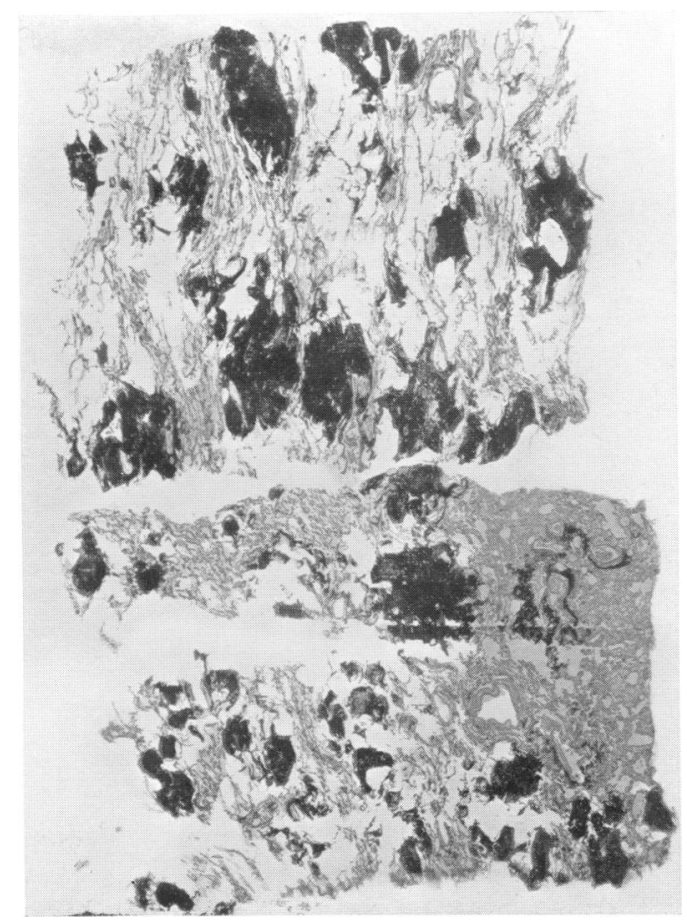

Fig. 5 . 